\title{
Normal microspore production after cell fusion in Brachiaria jubata (Gramineae)
}

\author{
Andréa Beatriz Mendes-Bonato ${ }^{1}$, Claudicéia Risso-Pascotto ${ }^{1}$, Maria Suely Pagliarini ${ }^{1}$ \\ and Cacilda Borges do Valle ${ }^{2}$ \\ ${ }^{1}$ Universidade Estadual de Maringá, Departamento de Genética e Biologia Celular, Maringá, PR, Brazil. \\ ${ }^{2}$ Embrapa Gado de Corte, Campo Grande, MS, Brazil.
}

\begin{abstract}
Cytogenetic studies were carried out on 22 accessions of Brachiaria jubata from the Embrapa Beef Cattle Brachiaria collection. One accession was diploid $(2 n=2 x=18)$ and the remaining 21 were tetraploid $(2 n=4 x=36)$. Among five tetraploid accessions, a specific and constant pattern of cell fusion involving only two microsporocytes was recorded. Meiosis proceeded normally from prophase I to the end, giving rise to an octad with normal microspores that developed into fertile pollen grains. Regular octad formation was possible because each cellular chromosome set was maintained in its proper domain, spindles were correctly positioned, and cytokinesis planes were formed in the correct places. Such behavior of meiosis in syncytes has never been reported in any other plant species.
\end{abstract}

Key words: Brachiaria jubata, cell fusion, microsporogenesis, pollen fertility.

Received: March 25, 2003; Accepted: August 15, 2003.

\section{Introduction}

Microsporogenesis is the developmental process leading to the production of four haploid microspores from a diploid pollen mother cell by means of meiosis and cytokinesis. Two types of cytokinesis have been reported in the microsporogenesis of flowering plants: successive and simultaneous (Maheshwari, 1950). In the successive type, a callose wall is deposited after the first meiotic division, forming a dyad, so that the two nuclei undergoing the second meiotic division are separated. In the simultaneous type, the first meiotic division is followed directly by the second, and then cytokinesis and callose deposition occur, forming four microspores (Furness et al., 2002). Although cytokinesis is predominantly of the successive type among monocotyledons, Furness and Rudall (1999) demonstrated that microsporogenesis is a significant character at the ordinal level, and simultaneous microsporogenesis has evolved independently in several monocot groups. The arrangement of the four microspores is varied, resulting in differently shaped tetrads (Furness et al., 2002).

In the Brachiaria genus, cytokinesis is of the successive type producing a tetragonal (or isobilateral) tetrad (Mendes-Bonato et al., 2002 a). In this genus, cytological characterization in species of agronomic interest has shown

Send correspondence to Maria Suely Pagliarini. Universidade Estadual de Maringá, Departamento de Genética e Biologia Celular, 87020-900 Maringá, PR, Brazil. E-mail: mspagliarini@uem.br. several meiotic abnormalities (Mendes-Bonato et al., 2001 a, b, 2002 b; Junqueira Filho et al., 2003; Risso-Pascotto et al., 2002, $2003 \mathrm{a}, \mathrm{b}$ ), including different patterns of cell fusion (Mendes-Bonato et al., 2001 a, c; Risso-Pascotto et al., 2003 b). All meiotic abnormalities reported harmed pollen fertility by generating unbalanced gametes. But, in the specific case of cell fusion, microspore production was completely abnormal because cytokinesis after telophase I did not happen, and the second division phases occurred in the syncytial mass mixing the segregated genomes. Microspores of different sizes, with different amounts of nuclei, were reported in these cases (Mendes-Bonato et al., $2001 \mathrm{a}$, c; Risso-Pascotto et al., 2003 b).

Interspecific hybridization has been aimed in Brachiaria, an important forage grass genus of African origin, widely used in pastures in the Brazilian tropics since 1960s. The two most cultivated varieties, B. brizantha $\mathrm{cv}$. Marandu and $B$. decumbens cv. Basilisk, were selected from natural genetic variability, but lack some important agronomical traits, such as resistance to spitllebugs and soil acidity, characteristics that make them vulnerable. To minimize the problem, the creation of new genetic combinations from intra- and interspecific hybridization is under development at Embrapa Beef Cattle, in a specific program dedicated to Brachiaria breeding. However, this program presents several obstacles because the majority of accessions among Brachiaria species are polyploids, mainly tetraploids, and polyploidy is correlated with apomixis. 
The program aims at producing fertile hybrids by crosses using sexual accessions as female genitor. Some interspecific hybrids have been synthetized by the breeding program since 1988 and are under cytological and agronomical evaluation.

Brachiaria jubata is a species widely distributed in tropical Africa (Keller-Grein et al., 1996) and its interest to the Brazilian breeding program lies in the possibility of using interspecific hybridization to transfer high resistance to spittlebugs, the major pest in Brachiaria pastures. Resistance to this insect was identified in one accession of $B$. jubata. During cytogenetic characterization of 22 accessions of this species in the germplasm collection at Embrapa Beef Cattle Research Center, five accessions presented a specific pattern of cell fusion involving two microsporocytes. Its behavior from prophase I to the end of meiosis is discussed.

\section{Material and Methods}

Cytogenetic studies were carried out on 22 accessions of Brachiaria jubata from the Embrapa Beef Cattle Brachiaria collection, kept in Campo Grande (state of Mato Grosso do Sul, Brazil) which comprises 475 accessions of 15 species.

Inflorescences at the ideal stage for meiotic study were collected and fixed in a mixture of ethanol $95 \%$, chloroform and propionic acid $(6: 3: 2)$ for $24 \mathrm{~h}$, transferred to $70 \%$ alcohol and stored under refrigeration until use. Microsporocytes were prepared by squashing and staining with $0.5 \%$ propionic carmine. All meiotic phases were evaluated in inflorescences collected from four plants of each accession. Photomicrographs were made with a Wild Leitz microscope using Kodak Imagelink - HQ, ISO 25 black and white film.

\section{Results and Discussion}

Cytogenetic studies revealed that among 22 accessions of $B$. jubata analyzed, one was diploid $(2 \mathrm{n}=2 \mathrm{x}=18)$ and the remaining 21 were tetraploid $(2 n=4 x=36)$. Five tetraploid accessions presented a specific and constant pattern of cell fusion never reported for the genus. In these accessions, since prophase I, cell fusions involving only two microsporocytes were found (Figure 1). The frequency of fusions was low in all accessions, ranging from $2.45 \%$ in the accession BRA 005509 to $6.61 \%$ in BRA 004332 (Table 1).

Cell fusion is a phenomenon widely reported in certain plant species (Smith, 1942; Stern, 1946; Price, 1956; Kamra, 1960 a, b; Pantulu and Manga, 1971; Rao and Koduru, 1978; Peeters et al., 1985; Rao et al., 1991; Nirmala and Rao, 1996; Caetano-Pereira et al., 1998, 1999). In the genus Brachiaria, cell fusion had been recently reported to occur in $B$. decumbens (Mendes-Bonato et al., 2001 a) and B. brizantha (Mendes-Bonato et al.,
2001 c; Risso-Pascotto et al., 2003 b). In all Brachiaria reports, fusion involved from two to several cells, sometimes more than twenty.

In several species, including those of the Brachiaria genus, meiotic division in syncytes has been reported to be abnormal. In some cases, meiosis did not go beyond prophase I; in others, chromosomes were clumped by stickiness, forming several pycnotic nuclei that soon degenerated; sometimes, the nuclei coalesced, forming a polyploid nucleus; and, in other cases, meiosis occurred, but was not always followed by correct cytokinesis. In the last cases, giant microspores with one to several nuclei, including the polyploid ones, were reported (see Caetano-Pereira et al., 1998, 1999; Mendes-Bonato et al., 2001 a, c). In the $B$. jubata accessions under analysis, despite cell fusion, meiosis proceeded normally from prophase I to the end, giving rise to an octad with normal microspores. According to Baskin and Cande (1990), the spindle is responsible for determining where and when partition will occur. Regular octad formation was possible because each cellular chromosome set was maintained in its proper domain, spindles were correctly positioned, and cytokinesis planes were formed in the correct places. Figure 1 illustrates well both meiotic divisions in the fusionned cells. After telophase I (Figure 1e), two planes of cytokinesis occurred in both sister nuclei (Figure 1f). After occurrence of cytokinesis, two non-sister nuclei remained in the same cytoplasm (Figure 1f). Before the beginning of the second division, an additional cytokinesis occurred in all fused cells, partitioning the mass into four cells (Figure 1g), that underwent meiosis II independently (Figure 1h-k). At the end of telophase II, a third cytokinesis occurred (Figure 1j), giving rise to an octad with normal microspores (Figure 1k) that developed into fertile pollen grains (Figure 11). Sterile pollen grains from syncytes have been reported in Hordeum vulgare (Smith, 1942), Kniphofia (Moffet, 1932), maize (CaetanoPereira et al., 1998, 1999), and also in the Brachiaria genus (Mendes-Bonato et al., 2001 a, c).

A syncyte is a plasmodial mass containing more than one nucleus that may occur individually or coalesced, forming polyploid nuclei (Nirmala and Rao, 1996). According to these authors, syncytes may be formed by suppression of cell wall formation during premeiotic mitoses (archesporial syncytes), or by fusion among microsporocytes caused by dissolution of the cell wall at the prophase I (fusional syncytes). In the present accessions of B. jubata, as the fusion involved only two cells with individualized nucleus, and most of them presented regular contour, we suggest that they resulted from suppression of cell wall formation in the last premeiotic mitosis.

The causes for syncyte formation may be diverse. Chemicals, X-rays, temperature, and culture conditions (Stern, 1946; Pantulu and Manga, 1971; Peeters et al., 1985) and genetic factors (Pantulu and Manga, 1971; Rao and Koduru, 1978; Rao et al., 1991; Nirmala and Rao, 


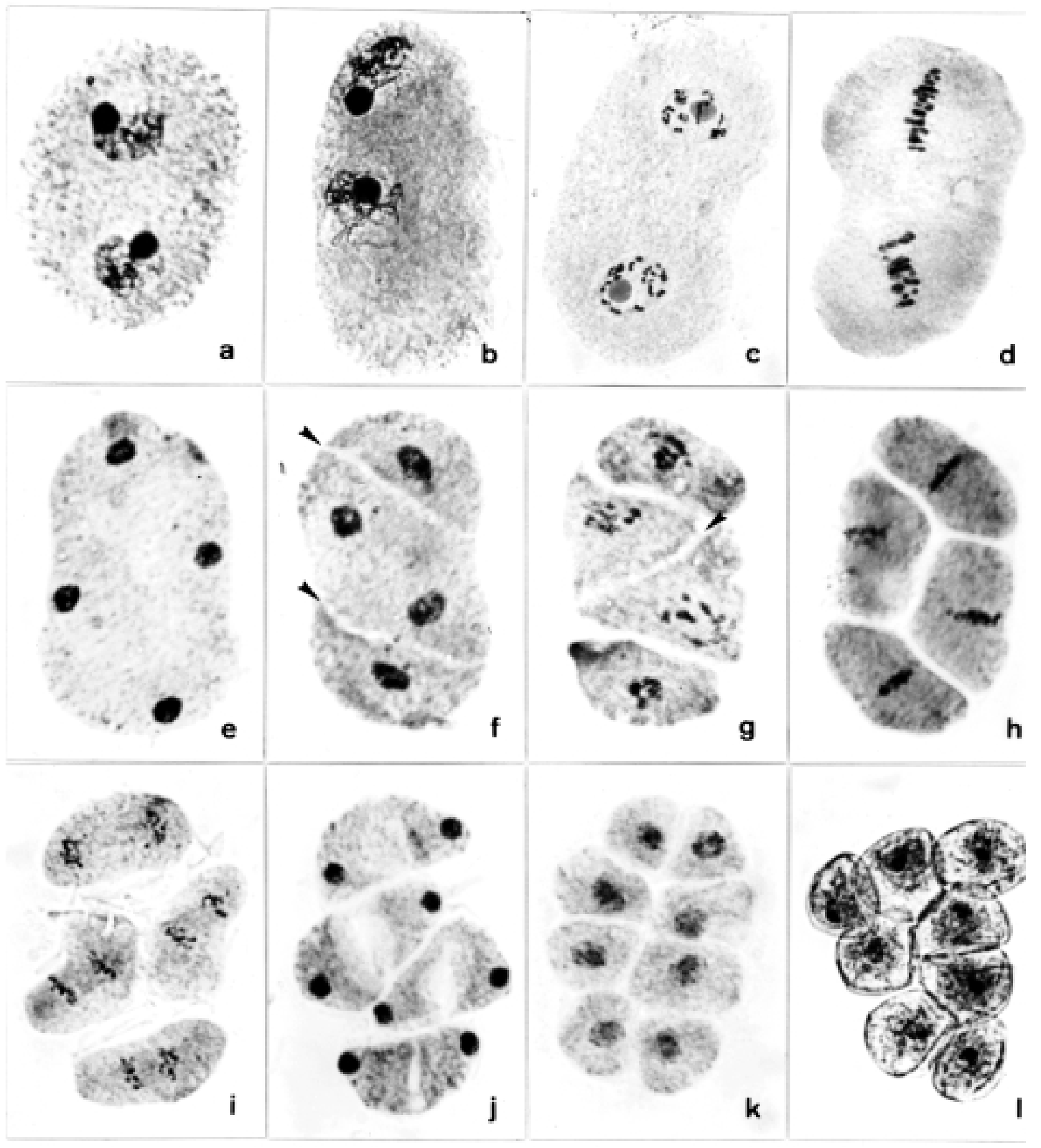

Figure 1 - Microsporogenesis in syncytes of B. jubata. a) Zygotene. b) Pachytene. c) Diakinesis. d) Metaphase I. e) Telophase I. f) Normal cytokinesis after telophase I (arrowhead). g) Additional cytokinesis before prophase II (arrowhead). h) Metaphase II. i) Anaphase II. j) Telophase II with normal cytokinesis. k) Octad. 1) Pollen grains.

1996) may influence cell fusion in higher plants. Considering that all the $B$. jubata accessions showing cell fusion were cultivated in the same environmental conditions, results suggest that the character is under genetic control, as was also proposed by Mendes-Bonato et al. (2001c) for one accession of $B$. brizantha.
In the Brachiaria genus, polyploid accessions are, in general, apomictic, albeit pseudogamous. Consequently, fertile pollen is essential to fertilize the central nucleus of the embryo-sac and ensure viable seeds production. The cytogenetic studies performed on the Brachiaria collection have the objectives of identifying diploid accessions, deter- 
Table 1 - Number of analyzed cells and number of cell fusions per phase during microsporogenesis in five tetraploid accessions of $B$. jubata.

\begin{tabular}{|c|c|c|c|c|c|c|c|c|c|c|}
\hline \multirow[t]{2}{*}{ Accessions } & \multicolumn{9}{|c|}{ Phases } & \multirow{2}{*}{$\begin{array}{c}\text { No. of cells } \\
\text { analyzed } \\
\text { (\% fusion) }\end{array}$} \\
\hline & PI & MI & AI & TI & PII & MII & AII & TII & Octads & \\
\hline BRA 005215 & $142(7)$ & $156(5)$ & $156(4)$ & $147(9)$ & $146(6)$ & $122(3)$ & $121(3)$ & $153(5)$ & $167(4)$ & $1310(3.51)$ \\
\hline BRA 005509 & $135(0)$ & $162(8)$ & $135(5)$ & $144(6)$ & $144(3)$ & $172(3)$ & $154(2)$ & $144(3)$ & $168(3)$ & $1358(2.45)$ \\
\hline BRA 005401 & $289(27)$ & $169(14)$ & $136(9)$ & $174(11)$ & $124(4)$ & $161(2)$ & $116(0)$ & $166(0)$ & $190(15)$ & $1525(5.38)$ \\
\hline BRA 005355 & $362(18)$ & $189(12)$ & $113(7)$ & $173(7)$ & $125(2)$ & $160(0)$ & $81(0)$ & $157(0)$ & $217(13)$ & $1577(3.55)$ \\
\hline BRA 004332 & $348(35)$ & $166(19)$ & $112(7)$ & $170(17)$ & $117(1)$ & $133(2)$ & $99(0)$ & $145(0)$ & $162(15)$ & $1452(6.61)$ \\
\hline
\end{tabular}

mining which polyploid ones present regular meiosis to participate in intra- or interespecific hybridization, as well as studying specific chromosomal behavior in previously unknown species and accessions. The abnormality reported here did not harm pollen fertility per se. However, as expected in tetraploid accessions, characteristic abnormalities related to this ploidy level were frequent, and caused some pollen sterility.

\section{References}

Baskin TI and Cande WZ (1990) The structure and function of the mitotic spindle in flowering plants. Annu Rev Plant Physio Plant Mol Biol 41:277-315.

Caetano-Pereira CM, Defani-Scoarize MA, Pagliarini MS and Brasil EM (1998) Syncytes, abnormal cytokinesis and spindle irregularities in maize microsporogenesis. Maydica 43:235-242.

Caetano-Pereira CM, Pagliarini MS and Brasil EM (1999) Cell fusion and chromatin degeneration in a maize inbred line. Genet Mol Biol 22:69-72.

Furness CA and Rudall PJ (1999) Microsporogenesis in monocotyledons. Ann Bot 84:475-499.

Furness CA, Rudal PJ and Sampson BF (2002) Evolution of microsporogenesis in angiosperms. Int J Plant Sci 163:235-260.

Junqueira Filho RG, Mendes-Bonato AB, Pagliarini MS, Bione NCP, Valle CB and Penteado MIO (2003) Absence of microspore polarity, symmetric divisions and pollen cell fate in Brachiaria decumbens (Gramineae). Genome 46:83-88.

Kamra OP (1960 a) Occurrence of binucleate and multinucleate pollen mother cells in Hordeum. Hereditas 46:536-542.

Kamra OP (1960 b) Chromatin extrusion and cytomixis in pollen mother cells of Hordeum. Hereditas 46:592-600.

Keller-Grein G, Maass BL and Hanson J (1996) Natural variation in Brachiaria and existing germplasm collection. In: Miles JW, Maass BL and Valle CB (eds) Brachiaria: Biology, Agronomy and Improvement. CIAT/Embrapa. pp 17-42.

Maheshwari P (1950) An Introduction to the Embriology of Angiosperms. McGraw-Hil, New York.

Mendes-Bonato AB, Pagliarini MS, Silva N and Valle CB (2001 a) Meiotic instability in invader plants of signal grass Brachiaria decumbens Stapf (Gramineae). Acta Scientiarum 23:619-625.

Mendes-Bonato AB, Pagliarini MS, Valle CB and Penteado MIO (2001 b) A severe case of chromosome stickiness in pollen mother cells of Brachiaria brizantha (Hochst) Stapf (Gramineae). Cytologia 66:287-291.
Mendes-Bonato AB, Pagliarini MS, Valle CB and Penteado MIO (2001 c) Archesporial syncytes restricted to male flowers in a hexaploid accession of Brachiaria brizantha (Hochst) Staph (Gramineae). Nucleus 44:137-140.

Mendes-Bonato AB, Pagliarini MS, Forli F, Valle CB and Penteado MIO (2002 a) Chromosome numbers and microsporogenesis in Brachiaria brizantha (Gramineae). Euphytica 125:419-425.

Mendes-Bonato AB, Junqueira Filho RG, Pagliarini MS, Valle $\mathrm{CB}$ and Penteado MIO (2002 b) Unusual cytological patterns of microsporogenesis in Brachiaria decumbens: abnormalities in spindle and defective cytokinesis causing precocious cellularization. Cell Biol Int 26:641-646.

Moffet AF (1932) Studies on the formation of multinuclear giant pollen grain in Kniphophia. J Genet 25:315-337.

Nirmala A and Rao PN (1996) Genesis of chromosomal numerical mosaicism in higher plants. Nucleus 39:151-175.

Pantulu JV and Manga V (1971) Monofactorial "multiploid sporocytes" condition induced by EMS in pearl millet. Genetica 42:214-218.

Peeters JP, Griffiths JF and Wilkes G (1985) In vivo karyotypic modifications following spontaneous cell fusion in maize (Zea mays L.). Can J Genet Cytol 27:580-585.

Price S (1956) Cytological studies in Saccharum and allied genera. I. Syncytes in certain clones of Saccharum and Erianthus. Cytologia 21:21-37.

Rao MK and Koduru PKR (1978) Cytogenetics as a factor for syncyte formation and male sterility in Pennisetum americanum. Theor Appl Genet 3:1-7.

Rao PN, Nirmala A and Ranganadham P (1991) Cytogenetic studies of plasmodial sporocytes, chromatin disintegration, desynapsis and centromere breakage in pearl millet. Cytologia 56:165-171.

Risso-Pascotto C, Pagliarini MS and Valle CB (2002) Abnormal nucleolar cycle in microsporogenesis of Brachiaria decumbens (Gramineae). Cytologia 67:355-360.

Risso-Pascotto C, Pagliarini MS and Valle CB (2003 a) A mutation in the spindle checkpoint arresting meiosis II in Brachiaria ruziziensis. Genome 46:724-728.

Risso-Pascotto C, Pagliarini MS, Valle CB and Mendes-Bonato $\mathrm{AB}$ (2003 b) Chromosome number and microsporogenesis in a pentaploid accession of Brachiaria brizantha (Gramineae). Plant Breed 122:136-140.

Smith L (1942) Cytogenetics of a factor for multiploid sporocytes in barley. Am J Bot 29:451-456.

Stern H (1946) The formation of polynucleated pollen mother cells. J Hered 37:46-50. 